\title{
Amikacin Pharmacokinetics During Continuous Veno-Venous Hemodialysis
}

Simon W. Lam $\cdot$ Seth R. Bauer

To view enhanced content go to www.infectiousdiseases-open.com

Received: May 13, 2013 / Published online: August 16, 2013

(c) The Author(s) 2013. This article is published with open access at Springerlink.com

\begin{abstract}
$(11.7-17.3 \mathrm{mg} / \mathrm{kg})$

and

$23.9 \mathrm{~mL} / \mathrm{kg} / \mathrm{h}$

(19.0-29.5 mL/kg/h),

respectively. This

Introduction: Little is known about the pharmacokinetics of amikacin during continuous renal replacement therapy.

Methods: This prospective observational study included patients admitted to an academic medical center who received amikacin therapy while on continuous veno-venous hemodialysis

corresponded with a median $C_{\max }$ of $28.5 \mu \mathrm{g} /$ $\mathrm{mL}(20.9-39.0 \mu \mathrm{g} / \mathrm{mL})$. There was a significant correlation between clearance and dialytic dose (for every $1 \mathrm{~L} / \mathrm{h}$ increase in dialysate flow rate, clearance rate increased by $23.6 \mathrm{~mL} / \mathrm{min}$ [95\% confidence interval $1.7-45.4 \mathrm{~mL} / \mathrm{min}$; $P=0.037])$.
\end{abstract} (CVVHD) and had at least two serum sample concentrations measured after first-dose administration. First-order pharmacokinetic parameters, patient characteristics, and CVVHD parameters were recorded.

Results: Fifteen patients were included in the analysis. The median (interquartile range) dose of amikacin and dialysate flow rate, based on adjusted body weight, were $14.1 \mathrm{mg} / \mathrm{kg}$

S. W. Lam ( $\square) \cdot$ S. R. Bauer

Department of Pharmacy, Cleveland Clinic

Health System, 9500 Euclid Avenue, Cleveland, OH 44195, USA

e-mail: lams@ccf.org

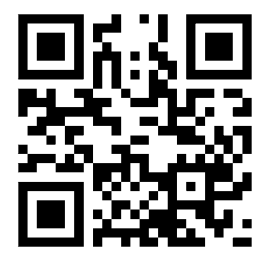

Enhanced content for this article is

available on the journal web site:

www.infectiousdiseases-open.com
Conclusion: The results of this study suggest that amikacin dose and interval should be individualized for each patient on CVVHD based on first-dose pharmacokinetic assessment.

Keywords: Amikacin; Continuous renal replacement therapy; Pharmacokinetics

\section{INTRODUCTION}

Infection is common among critically ill patients and is associated with considerable morbidity and mortality $[1,2]$. In a large, 1-day, cross-sectional study of intensive care unit (ICU) patients, 51\% were considered infected, while $71 \%$ were receiving antibiotics [3]. Among ICU patients infected with 
Gram-negative bacteria, the incidence of resistance continues to rise [4]. Optimal and timely antibiotic treatment of critically ill, infected patients is paramount to maximizing survival $[5,6]$. Given the epidemiological trends of Gram-negative pathogens and the increased incidence of resistance, many treatment guidelines recommend the use of empiric dual Gram-negative coverage, which frequently includes the use of an aminoglycoside [7-9]. The Surviving Sepsis Campaign guidelines further recommend that adequate initial doses of antibiotics should be given to ensure that serum concentrations are attained to maximize efficacy and minimize toxicity; nevertheless, these antibiotic doses are infrequently evidence based in critically ill patients [10].

Infected patients may develop a spectrum of biologic response, ranging from systemic inflammatory response syndrome to septic shock and death. Acute renal failure occurs proportionally to the extent of the biologic response to infection, ranging from $19 \%$ in patients with sepsis to $51 \%$ in patients with septic shock [11, 12]. Among critically ill patients with acute kidney injury requiring renal replacement therapy, continuous renal replacement therapy (CRRT) is frequently used [13].

Understanding the pharmacokinetic (PK) characteristics of aminoglycoside during CRRT warrants further investigation, given the importance of attaining adequate antibiotic serum concentrations and the increasing need for this class of antimicrobials in critically ill patients. Among the aminoglycosides, amikacin is useful for gentamicin-resistant Gram-negative pathogen infections or as empiric treatment in institutions with a local epidemiological pattern suggesting the need to use this medication [14]. Despite its crucial role in therapy, a survey of the literature reveals a relative paucity of amikacin PK data among critically ill patients. In particular, there are fewer than 50 reports of amikacin PK parameters during CRRT [15-22]. Despite the availability of these reports, their clinical applicability is limited by a number of factors.

CRRT generally removes toxins and drugs through either diffusive and/or convective processes. Drug clearance for a particular medication may be affected by the mode of CRRT used, inter- and intra-patient variation in dialytic dose, and institutional variations in CRRT machines and filters. The majority of the reports on amikacin PK characteristics during CRRT were from a period of time where CRRT was performed with relatively lower dialysate or replacement fluid flow rates $(0.6-1.2 \mathrm{~L} / \mathrm{h})$ compared to current CRRT prescriptions (2-4 L/h), or with hemofilters no longer used in clinical practice [15-18]. In addition, few of the reports provided the characteristics of the dialysis machine, the mode of CRRT, and filter details. Lastly, only one report describes the PK characteristics of amikacin in patients undergoing continuous veno-venous hemodialysis (CVVHD) [16]. There are several reports of amikacin PK with novel CRRT parameters; however, they comprise fewer than 30 cases in total. Furthermore, some novel reports of amikacin PK characteristics involved five or fewer patients in their analysis $[21,22]$ and one report focused on patients with burn injury [20], which may have confounding PK implications. Given the paucity of data and the continued need for broad-spectrum antibiotics targeting Gram-negative pathogens in an era of newer CRRT machines and filters with drastically higher flow rates, the PK characteristics of amikacin warrant further investigation. As such, we performed a prospective observational study of patients who received amikacin therapy while on 
CVVHD to further characterize the PK parameters of the medication.

\section{MATERIALS AND METHODS}

This was a prospective observational study of a convenient sample of patients admitted to a medical ICU of a tertiary care academic medical center, who received amikacin therapy while on CVVHD. Patient characteristics, amikacin dosing, and CVVHD parameters, including machine, filter, effluent, and dialysate flow rates, were collected from an intensive care database that was approved by the Cleveland Clinic Institutional Review Board (IRB). The database was approved by the local IRB as part of a registry for the evaluation of intensive care pharmacotherapy-related outcomes. The current study was performed by querying the existing data within the registry with no additional information collected through chart review or patient contact. A waiver of informed consent was granted by the local IRB.

The decision to administer amikacin and the prescribed dose/frequency were determined by the primary ICU service, and not prescribed by the study protocol. Patients with at least two amikacin serum sample concentrations measured after the first dose of amikacin were included in the study. Serum amikacin concentration measurements were drawn as part of routine patient monitoring and levels were generally determined more than $8 \mathrm{~h}$ apart. Amikacin levels were measured by our local institutional laboratory using the Advia ${ }^{\circledR} 1200$ system (Siemens Medical Solutions, Malvern, PA, United States) chemistry analyzer with an enzyme immunoassay technique. The assay measures total amikacin level and has a quantification range of $2.5-50 \mu \mathrm{g} / \mathrm{mL}$, with a detection limit of $1 \mu \mathrm{g} / \mathrm{mL}$ and a coefficient of variation of approximately 10\%. First-order pharmacokinetics with a single compartment were assumed and estimations of the peak concentration $\left(C_{\max }\right)$, volume of distribution $\left(V_{\mathrm{d}}\right)$, elimination constant $\left(K_{\mathrm{el}}\right)$, clearance $(\mathrm{Cl})$, and terminal half-life $\left(t_{1 / 2}\right)$ were performed. The equations used to calculate the various PK criteria can be found in Table 1. All calculations were performed assuming all amikacin removal was from CRRT clearance alone. For all calculations, the ideal body weight (IBW) was used unless patients were more than $30 \%$ above their IBW. If patients were more than 30\% above their IBW, then a dosing weight (DW) was used [DW $=\mathrm{IBW}+0.4$ (actual weight in $\mathrm{kg}-\mathrm{IBW})$ ] [14].

The decision to administer CRRT was made as per recommendations from the nephrology ICU consult service. Selection of the machine for dialysis and filter choice were based upon chance equipment availability at the time of CVVHD initiation. However, in accordance with our local practice, CVVHD was performed using a Prismaflex ${ }^{\circledR}$ System (Gambro, Lakewood, CO, USA) or System One ${ }^{\mathrm{TM}}$ dialysis system (NxStage ${ }^{\circledR}$, Lawrence, MA, USA) with either a polyacrylonitrile [(AN69)Prismaflex M100, $0.9 \mathrm{~m}^{2}$ membrane surface area] or a polysulfone hemofilter (NxStage Cartridge

Table 1 Pharmacokineticformulas

\begin{tabular}{ll}
\hline Pharmacokinetic parameter & Equation \\
\hline Elimination constant $\left(k_{\mathrm{el}}\right), \mathrm{h}^{-1}$ & $\ln \left(C_{2} / C_{1}\right) /\left(t_{2}-t_{1}\right)$ \\
Half-life $\left(t_{1} / 2\right), \mathrm{h}$ & $0.693 / k_{\mathrm{el}}$ \\
Projected peak $\left(C_{\max }\right), \mu \mathrm{g} / \mathrm{mL}$ & $C_{1} / \ln \left(e^{-k_{\mathrm{el}} \times \Delta t}\right)$ \\
Volume of distribution $\left(V_{\mathrm{d}}\right), \mathrm{L}$ & $D / C_{\max }$ \\
Clearance $(\mathrm{Cl}), \mathrm{mL} / \mathrm{min}$ & $V_{\mathrm{d}} \times k_{\mathrm{el}}$ \\
\hline
\end{tabular}

$\Delta t$ time between first concentration drawn and $30 \mathrm{~min}$ after infusion completion, $C_{1}$ first measured concentration, $C_{2}$ second measured concentration, $D$ dose, $t_{1}$ time when first concentration was drawn, $t_{2}$ time when second concentration was drawn 
Express, $1.5 \mathrm{~m}^{2}$ membrane surface area), respectively. The CVVHD parameters, including blood flow rate, dialysate flow rate, ultrafiltration rate, or the need for filter anticoagulation, were determined by the nephrology ICU consult service based on individual patient needs. In general, an ultrafiltration rate ranging from 50 to $150 \mathrm{~mL} / \mathrm{h}$ was added to the CVVHD dialysate rate to optimize machine running time and facilitate volume removal (as determined by the nephrology and primary ICU services). Because this ultrafiltration rate was relatively small compared to the dialysate rate (about 5\%), the dialysis modality was still considered CVVHD, as opposed to continuous veno-venous hemodiafiltration, or CVVHDF.

\section{Statistical Analysis}

Continuous data are presented as median (interquartile range, IQR), unless otherwise specified. Pearson correlation was utilized to assess the relationship between amikacin PK parameters and CVVHD characteristics. Linear regression was performed to evaluate the relationship between the dose administered and the projected peak amikacin concentration, as well as the relationship between dialysate flow rate and amikacin clearance. Statistics were computed using SPSS software, version 15.0 (SPSS Inc., Chicago, Illinois), and a $P$ value $<0.05$ was considered statistically significant.

\section{RESULTS}

Fifteen patients were included in the analysis. Their median (IQR) age was 56 (45-67) years with a median (IQR) weight of $84(64-117) \mathrm{kg}$.
Only two of the patients had end-stage renal disease, while the remainder required CRRT due to acute kidney injury. Patients had minimal residual renal function with a median (IQR) urine output of $10(0-52) \mathrm{mL}$ in the $24 \mathrm{~h}$ after amikacin administration. The patients were all critically ill with a median (IQR) APACHE II score of 25 (22-30), with 14 (93\%) requiring mechanical ventilation.

Four patients $(26.7 \%)$ were dialyzed using the NxStage machine with NxStageCartridge Express polysulfone filter, while 11 (73.3\%) patients were dialyzed using the Prismaflex machine with the M100 acrylonitrile filter. The individual dialysis characteristics are shown in Table 2. The median (IQR) age of the dialysis filter at the time of amikacin administration was $10(3-28) \mathrm{h}$. Minimal interruption in continuous dialysis was observed during the amikacin sampling period, with a median (IQR) interruption time of $15 \quad(0-300) \mathrm{min}$. The median (IQR) dialysate, weight-adjusted dialysate, ultrafiltration, and blood flow rates were $2,000 \quad(1,825-2,450) \mathrm{mL} / \mathrm{h}, \quad 23.9(19.0-29.5)$ $\mathrm{mL} / \mathrm{kg} / \mathrm{h}, \quad 50(50-100) \mathrm{mL} / \mathrm{h}, \quad$ and 200 (150-200) $\mathrm{mL} / \mathrm{min}$, respectively.

The median (IQR) dose of amikacin, based on adjusted body weight (DW), was 14.1 $(11.7-17.3) \mathrm{mg} / \mathrm{kg}$. The individual amikacin dose and PK parameters are presented in Table 3. The amikacin dose administered corresponded with a median (IQR) projected $C_{\max }$ of $28.5(20.9-39.0) \mu \mathrm{g} / \mathrm{mL}$. The $V_{\mathrm{d}}, \mathrm{Cl}$, and $t_{1 / 2}$ were $0.39 \quad(0.28-0.57) \mathrm{L} / \mathrm{kg}, \quad 36.7$ (22.8-44.5) $\mathrm{mL} / \mathrm{min}$, and 12.7 (8.7-16.7) h, respectively. Correlation analyses found a significant correlation between clearance and dialytic dose. Using simple linear regression, for every $1 \mathrm{~L} / \mathrm{h}$ increase in dialysate flow rate, the clearance rate increased by $23.6 \mathrm{~mL} / \mathrm{min}(95 \%$ CI $1.7-45.4 \mathrm{~mL} / \mathrm{min} ; P=0.037)$. In addition, 
Table 2 Individual characteristics of continuous veno-venous hemodialysis parameters

\begin{tabular}{llllcr}
\hline $\begin{array}{l}\text { Patient } \\
\text { number }\end{array}$ & Machine & $\begin{array}{l}\text { Blood flow } \\
(\mathbf{m L} / \mathbf{m i n})\end{array}$ & $\begin{array}{l}\text { Dialysate rate } \\
(\mathbf{m L} / \mathbf{h})\end{array}$ & $\begin{array}{l}\text { Effluent rate } \\
(\mathbf{m L} / \mathbf{h})\end{array}$ & $\begin{array}{l}\text { Age of filter } \\
(\mathbf{h})\end{array}$ \\
\hline 1 & Prismaflex & 200 & 2,500 & 50 & 40.0 \\
2 & Prismaflex & 150 & 2,000 & 100 & 23.5 \\
3 & Prismaflex & 160 & 2,350 & 50 & 9.0 \\
4 & Prismaflex & 200 & 3,000 & 100 & 10.0 \\
5 & NxStage & 150 & 2,800 & 50 & 3.0 \\
6 & Prismaflex & 200 & 2,000 & 150 & 43.0 \\
7 & Prismaflex & 150 & 2,400 & 50 & 0.5 \\
8 & Prismaflex & 150 & 2,000 & 50 & 1.5 \\
9 & NxStage & 150 & 1,200 & 50 & 0.5 \\
10 & Prismaflex & 200 & 1,800 & 50 & 28.0 \\
11 & NxStage & 200 & 1,600 & 50 & 8.0 \\
12 & Prismaflex & 200 & 2,500 & 100 & 3.8 \\
13 & NxStage & 200 & 2,000 & 100 & 22.5 \\
14 & Prismaflex & 160 & 1,850 & 50 & 47.0 \\
15 & Prismaflex & 200 & 1,800 & 50 & 10.0 \\
\hline
\end{tabular}

the dose administered corresponded significantly with the projected peak amikacin serum concentration (Fig. 1).

\section{DISCUSSION}

In this study of a convenient sample of patients who received amikacin while on CVVHD, a significant positive correlation was found between amikacin clearance rate and dialysate flow rates. All patients in this study were treated with CVVHD utilizing synthetic dialysis filters and relatively high dialysate flow rates. The dialytic dose used in this study was complementary to those described by a recent survey of the management of critically ill patients with acute renal failure [23]. Despite the correlation between amikacin clearance and dialysate flow rates, the wide range of projected
$C_{\max }$ and $t_{1 / 2}$ seen in this study indicate that the exact amikacin dosing regimen cannot be accurately predicted based on the dialytic dose or other factors available at the bedside. As such, it would appear to be most appropriate to perform first-dose PK calculations to determine the appropriate dosing regimen for each patient.

Among many Gram-negative species across the world, the minimum inhibitory concentration to inhibit $90 \%$ of bacterial isolates $\left(\mathrm{MIC}_{90}\right.$ ) for amikacin is $8 \mu \mathrm{g} / \mathrm{mL}$ [24]; optimal antibacterial activity is achieved when the amikacin $C_{\max }$ is eight to ten times greater than the MIC. Based on the projected PK from this analysis, to achieve a peak of $64 \mu \mathrm{g} / \mathrm{mL}$ (8-times an MIC of $8 \mu \mathrm{g} / \mathrm{mL}$ ), a projected dose of about $25 \mathrm{mg} / \mathrm{kg}$ (based on DW) is needed. This is consistent with a recent report by Taccone and colleagues, who studied PK parameters after 
Table 3 Amikacin pharmacokinetic parameters

\begin{tabular}{lrllllll}
\hline $\begin{array}{l}\text { Patient } \\
\text { number }\end{array}$ & $\begin{array}{l}\text { Dose } \\
(\mathbf{m g})\end{array}$ & $\begin{array}{l}\text { Dose } \\
(\mathbf{m g} / \mathbf{k g})^{*}\end{array}$ & $\begin{array}{l}\boldsymbol{C}_{\mathbf{m a x}} \\
(\boldsymbol{\mu g} / \mathbf{m L})\end{array}$ & $\begin{array}{l}\boldsymbol{V}_{\mathbf{d}} \\
(\mathbf{L} / \mathbf{k g})^{*}\end{array}$ & $\begin{array}{l}\text { Clearance } \\
(\mathbf{m L} / \mathbf{m i n})\end{array}$ & $\boldsymbol{t}_{1 / 2}(\mathbf{h})$ & $\begin{array}{l}\text { Time to serum } \\
\text { level }<5 \boldsymbol{\mu g} \mathbf{m L}\end{array}$ \\
\hline 1 & 1,300 & 12.4 & 28.5 & 0.43 & 61.0 & 8.6 & 21.7 \\
2 & 750 & 11.7 & 37.7 & 0.31 & 37.7 & 6.1 & 17.8 \\
3 & 1,000 & 12.9 & 89.5 & 0.23 & 12.4 & 16.7 & 69.7 \\
4 & 1,000 & 12.2 & 19.8 & 0.61 & 36.7 & 15.9 & 31.6 \\
5 & 1,250 & 14.7 & 27.6 & 0.53 & 95.1 & 5.5 & 13.6 \\
6 & 1,250 & 21.1 & 60.1 & 0.35 & 18.9 & 12.7 & 45.6 \\
7 & 1,000 & 10.4 & 21.0 & 0.50 & 44.5 & 12.4 & 25.6 \\
8 & 750 & 10.5 & 24.3 & 0.43 & 20.1 & 17.8 & 40.5 \\
9 & 540 & 10.8 & 17.4 & 0.62 & 22.8 & 15.8 & 28.4 \\
10 & 1,000 & 14.2 & 31.3 & 0.45 & 37.2 & 9.9 & 26.3 \\
11 & 830 & 14.6 & 20.9 & 0.70 & 22.8 & 20.2 & 41.6 \\
12 & 1,500 & 17.3 & 19.5 & 0.89 & 43.1 & 20.6 & 40.5 \\
13 & 1,250 & 17.7 & 57.6 & 0.31 & 48.9 & 5.1 & 18.1 \\
14 & 1,000 & 18.3 & 39.0 & 0.68 & 30.1 & 14.2 & 42.2 \\
15 & 800 & 15.3 & 31.4 & 0.49 & 33.1 & 8.9 & 23.5 \\
\hline
\end{tabular}

* Per adjusted body weight

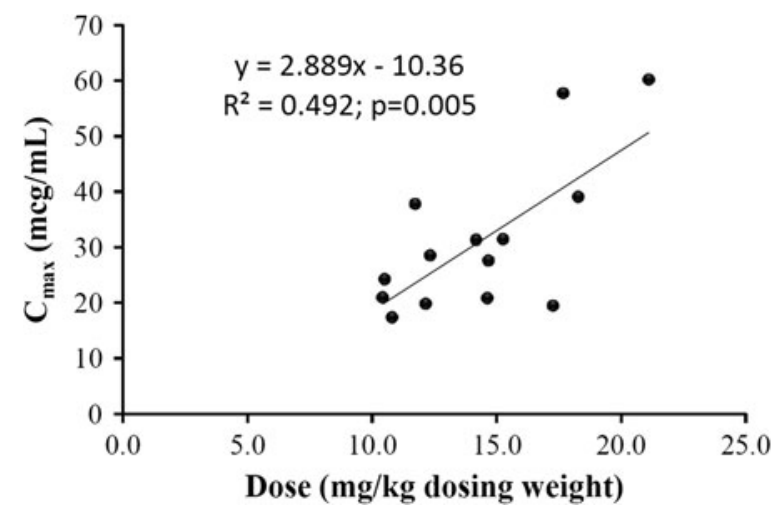

Fig. 1 Association between $C_{\max }$ and dose

a dose of $25 \mathrm{mg} / \mathrm{kg}$ of total body weight was administered to patients with severe sepsis and septic shock [25]. Among patients with renal dysfunction (defined as creatinine $\mathrm{Cl}<50 \mathrm{~mL}$ / min) in this study, a dose of $25 \mathrm{mg} / \mathrm{kg}$ achieved a $C_{\text {max }}, V_{\mathrm{d}}, \mathrm{Cl}$, and $t_{1 / 2}$ of $71.5 \mu \mathrm{g} / \mathrm{mL}, 0.42 \mathrm{~L} / \mathrm{kg}$,
$1.29 \mathrm{~mL} / \mathrm{min} / \mathrm{kg}$, and $7.6 \mathrm{~h}$, respectively. Remarkable similarities were seen between the $V_{\mathrm{d}}$ in the study by Taccone and colleagues [25] and that in the present study. In a subgroup of the patients from the Taccone study undergoing CVVHDF, the $t_{1 / 2}$ and $\mathrm{Cl}$ were $6.5 \mathrm{~h}$ and $1.26 \mathrm{~mL} /$ $\mathrm{kg} / \mathrm{min}$ (about $5.3 \mathrm{~L} / \mathrm{h}$ for a $70-\mathrm{kg}$ patient), respectively [19]. These values are drastically higher than those found in our study, which could be explained by the considerably higher dialytic dose used in that study (median dialysate and ultrafiltration rates of $29 \mathrm{~mL} /$ $\mathrm{kg} / \mathrm{h}$ and $33 \mathrm{~mL} / \mathrm{kg} / \mathrm{h}$, respectively, for an approximate total CRRT dose of $62 \mathrm{~mL} / \mathrm{kg} / \mathrm{h}$ ). Similarly, in a recent study of five patients undergoing CVVHDF, D'Arcy and colleagues [21] demonstrated an amikacin $t_{1 / 2}$ and $\mathrm{Cl}$ of $6.7 \mathrm{~h}$ and $56.6 \mathrm{~mL} / \mathrm{min}$, respectively. This study 
utilized an ultrafiltration rate of $2 \mathrm{~L} / \mathrm{h}$ and a dialysate rate of $1-2 \mathrm{~L} / \mathrm{h}$.

In contrast to the studies listed above, other studies have found considerably lower clearance rates than our study. Armendariz and colleagues presented a case report of a patient undergoing $\mathrm{CVVH}$ and found that total body clearance of amikacin was $10.5 \mathrm{~mL} / \mathrm{min}$ and $\mathrm{CVVH}$ clearance was $10.11 \mathrm{~mL} / \mathrm{min}$ [15]. This approximated the hemofiltration rate to be $10 \mathrm{~mL} / \mathrm{min}$. They found an elimination constant of $0.023 \mathrm{~h}^{-1}$, which corresponds to a $t_{1 / 2}$ of $29.7 \mathrm{~h}$. This study found clearance rates from CRRT to be similar to those reported for patients in renal failure without the use of dialysis. The median clearance rate of amikacin in our study $(36.7 \mathrm{~mL} / \mathrm{min})$ was drastically higher than that reported by Armendariz and colleagues. Of note, the dialysate flow rates described in the current report are approximately twice those reported by Armendariz and colleagues [15]. Given the high sieving coefficient of 0.93 for amikacin, it is conceivable that the flow rates during CRRT would dictate the amount of drug removal [26]. This premise is supported by other studies that utilized higher dialysate or ultrafiltration rates with subsequent findings of higher rates of amikacin clearance. Roberts and colleagues reported data from five patients on $\mathrm{CVVH}$, with average flow rates of $19.2 \mathrm{~mL} / \mathrm{min}(1.2 \mathrm{~L} /$ $\mathrm{h})$ and found a mean hemofiltration clearance rate of $16.4 \mathrm{~mL} / \mathrm{min}$ [18]. Taken together, it appears that across studies, the overall dialytic dose may affect amikacin clearance. This is consistent with the findings of our current study, which suggest that dialytic dose correlates with amikacin clearance. However, there are still many other factors that would ultimately determine the PK profile of amikacin. These may include inter-patient variability in non-dialytic measures, such as volume status, non-renal intrinsic clearance, the age of the filter, and interruptions to CVVHD.

Of interest, a study by Cotera and colleagues that evaluated amikacin clearance in five patients with acute oliguric renal failure undergoing CVVHD found that the amikacin clearance rates were only 3.57 and $4.18 \mathrm{~mL} / \mathrm{min}$ with 1 and $2 \mathrm{~L} / \mathrm{h}$ dialysate rates, respectively [16]. Even though the $2 \mathrm{~L} / \mathrm{h}$ dialysate rate was only slightly lower than that reported in the current study, the authors noted drastically lower clearance rates than in our study. This could potentially be explained by the type of hemodialyzer membrane utilized. Notably, all the previous studies discussed and the current study utilized synthetic hemodialyzer membranes composed of either acrylonitrile or polysulfone. In contrast, the study by Cotera and colleagues [16] utilized a cuprofen (cellulose) dialysis membrane. A decrease in drug clearance with the use of cellulose dialysis membranes compared to polysulfone has been well documented [27-30]. This may partially be explained by significant adsorption of aminoglycosides to synthetic membranes, which may contribute to an increase in overall clearance [31-33]. As such, all PK evaluations of aminoglycosides should readily report the type of filter, its age at the time of drug administration, and any potential filter changes during the PK sampling period.

Our study has several limitations. Similar to previous studies, the external validity of this study may be limited, given that all patients received CVVHD using either the Prismaflex or NxStage machine. Of note, only 4 of the 15 patients received dialysis via the Nxstage machine; therefore, the data presented here may be more applicable to patients receiving dialysis via the Prismaflex machine. Likewise, the considerable institutional differences in the 
practice of CRRT, including the mode, filter material, and dialysate and ultrafiltration rates, may limit the external applicability of this study. In addition, the methods used in the current study do not allow for differentiation between extracorporeal clearance and intrinsic clearance. The patients in our study had minimal residual kidney function, but in patients with some remaining renal function, clearance of amikacin may be higher. Lastly, the PK profiles evaluated in this study were obtained after the first dose of amikacin. Therefore, no conclusions could be made regarding the $\mathrm{PK}$ characteristics of amikacin beyond the initial dose. The strengths of our study include the largest number of patients evaluated to date and explicit notation of dialytic characteristics (which could affect PK parameters) that reflect more current practices with CRRT.

\section{CONCLUSION}

In conclusion, our study found a significant correlation between dialysate flow rate and amikacin clearance. Institutions should evaluate their usual dialytic practice to examine the flow rates routinely prescribed, which may provide a good starting estimate for amikacin clearance. However, given the considerable inter-individual variability observed in this study, an a priori prediction of PK parameters and optimal amikacin dose to be administered to patients on CVVHD may be challenging. Therefore, determination of the optimal dose of amikacin and dosing interval should be achieved by serum concentration monitoring and subsequent dose adjustments. Furthermore, the exact amikacin dosing regimen needs to be individualized based on the presumed MIC of the pathogen, site of infection, and other host factors. Due to the large number of potential confounders, which may include dialysate rate, ultrafiltration rate, hemodialyzer properties, patient residual intrinsic clearance, and host volume status, first-dose PK evaluations would be prudent in all critically ill patients on CRRT who are administered amikacin.

\section{ACKNOWLEDGMENTS}

No funding or sponsorship was received for this study or publication of this article. Dr. Simon Lam is the guarantor for this article and takes responsibility for the integrity of the work as a whole.

Conflict of interest. Simon Lam and Seth Bauer declare that they have no conflicts of interest.

Compliance with ethics guidelines. All procedures followed were in accordance with the ethical standards of the responsible committee on human experimentation (institutional and national) and with the Helsinki Declaration of 1975 , as revised in 2000. A waiver of informed consent was granted by the local institutional review board.

Open Access. This article is distributed under the terms of the Creative Commons Attribution Noncommercial License which permits any noncommercial use, distribution, and reproduction in any medium, provided the original author(s) and the source are credited.

\section{REFERENCES}

1. Angus DC, Linde-Zwirble WT, Lidicker J, et al. Epidemiology of severe sepsis in the United States: 
analysis of incidence, outcome, and associated costs of care. Crit Care Med. 2001;29:1303-10.

2. Vincent JL, Sakr Y, Sprung CL, et al. Sepsis in European intensive care units: results of the soap study. Crit Care Med. 2006;34:344-53.

3. Vincent JL, Rello J, Marshall J, et al. International study of the prevalence and outcomes of infection in intensive care units. JAMA. 2009;302:2323-9.

4. National Nosocomial Infections Surveillance System. National Nosocomial Infections Surveillance (NNIS) System Report, data summary from January 1992 through June 2004, issued October 2004. Am J Infect Control. 2004;32:470-85.

5. Ibrahim EH, Sherman G, Ward S, et al. The influence of inadequate antimicrobial treatment of bloodstream infections on patient outcomes in the ICU setting. Chest. 2000;118:146-55.

6. Kumar A, Roberts D, Wood KE, et al. Duration of hypotension before initiation of effective antimicrobial therapy is the critical determinant of survival in human septic shock. Crit Care Med. 2006;34:1589-96.

7. Guidelines for the management of adults with hospital-acquired, ventilator-associated, and healthcare-associated pneumonia. Am J Respir Crit Care Med. 2005;171:388-416.

8. Mermel LA, Allon M, Bouza E, et al. Clinical practice guidelines for the diagnosis and management of intravascular catheter-related infection: 2009 update by the Infectious Diseases Society of America. Clin Infect Dis. 2009;49:1-45.

9. Solomkin JS, Mazuski JE, Bradley JS, et al. Diagnosis and management of complicated intra-abdominal infection in adults and children: guidelines by the Surgical Infection Society and the Infectious Diseases Society of America. Clin Infect Dis. 2010;50:133-64.

10. Dellinger RP, Levy MM, Rhodes A, et al. Guidelines Committee including the Pediatric Subgroup. Surviving sepsis campaign: international guidelines for management of severe sepsis and septic shock: 2012. Crit Care Med. 2013;41: 580-637.

11. Rangel-Frausto MS, Pittet D, Costigan M, Hwang T, Davis CS, Wenzel RP. The natural history of the systemic inflammatory response syndrome (SIRS). A prospective study. JAMA. 1995;273:117-23.

12. Schrier RW, Wang W. Acute renal failure and sepsis. N Engl J Med. 2004;351:159-69.
13. Piccinni P, Cruz DN, Gramaticopolo S, et al. Prospective multicenter study on epidemiology of acute kidney injury in the ICU: a critical care nephrology Italian collaborative effort (NEFROINT). Minerva Anestesiol. 2011;77: 1072-83.

14. Edson RS, Terrell CL. The aminoglycosides. Mayo Clin Proc. 1999;74:519-28.

15. Armendariz E, Chelluri L, Ptachcinski R. Pharmacokinetics of amikacin during continuous veno-venous hemofiltration. Crit Care Med. 1990;18:675-6.

16. Cotera A, Aguila R, Gaete L, Saffie A, Lorca E, Thambo S. Pharmacokinetics and clearance of ciprofloxacin and amikacin in continuous hemodialysis. Rev Med Chil. 1995;123:742-8.

17. Joos B, Schmidli M, Keusch G. Pharmacokinetics of antimicrobial agents in anuric patients during continuous venovenous haemofiltration. Nephrol Dial Transplant. 1996;11:1582-5.

18. Robert R, Rochard E, Malin F, Bouquet S. Amikacin pharmacokinetics during continuous veno-venous hemofiltration. Crit Care Med. 1991;19:588-9.

19. Taccone FS, de Backer D, Laterre PF, et al. Pharmacokinetics of a loading dose of amikacin in septic patients undergoing continuous renal replacement therapy. Int $\mathrm{J}$ Antimicrob Agents. 2011;37:531-5.

20. Akers KS, Cota JM, Frei CR, et al. Once-daily amikacin dosing in burn patients treated with continuous venovenous hemofiltration. Antimicrob Agents Chemother. 2011;55:4639-42.

21. D'Arcy DM, Casey E, Gowing CM, Donnelly MB, Corrigan OI. An open prospective study of amikacin pharmacokinetics in critically ill patients during treatment with continuous venovenous haemodiafiltration. BMC Pharmacol Toxicol. 2012;13:14.

22. Yamamoto T, Yasuno N, Katada S, et al. Proposal of a pharmacokinetically optimized dosage regimen of antibiotics in patients receiving continuous hemodiafiltration. Antimicrob Agents Chemother. 2011;55:5804-12.

23. Ricci Z, Ronco C, D'Amico G, et al. Practice patterns in the management of acute renal failure in the critically ill patient: an international survey. Nephrol Dial Transplant. 2006;21:690-6.

24. Bertrand X, Dowzicky MJ. Antimicrobial susceptibility among gram-negative isolates 
collected from intensive care units in North America, Europe, the Asia-Pacific rim, Latin America, the Middle East, and Africa between 2004 and 2009 as part of the tigecycline evaluation and surveillance trial. Clin Ther. 2012;34:124-37.

25. Taccone FS, Laterre PF, Spapen $\mathrm{H}$, et al. Revisiting the loading dose of amikacin for patients with severe sepsis and septic shock. Crit Care. 2010;14:R53.

26. Golper TA, Wedel SK, Kaplan AA, et al. Drug removal during continuous arteriovenous hemofiltration: theory and clinical observations. Int J Artif Organs. 1985;8:307-12.

27. Gabutti L, Taminelli-Beltraminelli L, Marone C. Clearance of ceftriaxone during haemodialysis using cuprophane, haemophane and polysulfone dialysers. Eur J Clin Pharmacol. 1997;53:123-6.

28. Lanese DM, Alfrey PS, Molitoris BA. Markedly increased clearance of vancomycin during hemodialysis using polysulfone dialyzers. Kidney Int. 1989;35:1409-12.
29. Matzkies FK, Reinecke $H$, Tombach B, et al. Influence of dialysis procedure, membrane surface and membrane material on iopromide elimination in patients with reduced kidney function. Am J Nephrol. 2000;20:300-4.

30. Thalhammer F, Kletzmayr J, El Menyawi I, et al. Ofloxacin clearance during hemodialysis: a comparison of polysulfone and cellulose acetate hemodialyzers. Am J Kidney Dis. 1998;32:642-5.

31. Cigarran-Guldris $\mathrm{S}$, Brier ME, Golper TA. Tobramycin clearance during simulated continuous arteriovenous hemodialysis. Contrib Nephrol. 1991;93:120-3.

32. Kronfol NO, Lau AH, Barakat MM. Aminoglycoside binding to polyacrylonitrile hemofilter membranes during continuous hemofiltration. ASAIO Trans. 1987;33:300-3.

33. Tian $\mathrm{Q}$, Gomersall CD, Ip M, et al. Adsorption of amikacin, a significant mechanism of elimination by hemofiltration. Antimicrob Agents Chemother. 2008;52:1009-13. 